\title{
DESCOLONIZANDO AS PESQUISAS COM CRIANÇAS E TRÊS OBSTÁCULOS
}

\author{
ANETE ABRAMOWICZ* \\ TATIANe Cosentino Rodrigues ${ }^{* *}$
}

\begin{abstract}
RESUMO: Este artigo debate as possibilidades de descolonizar pesquisas com crianças, por meio de um entendimento de infância compreendida como experiência social e individual singular, que descentralize, ou faça fugir os modelos e lugares hegemônicos que centralizam sentidos, norma, estética e saúde dominantes e que se constitua para além da lógica do capital. Inicia-se o debate sobre a infância como um dispositivo do poder que se impõe a cada criança de maneira universal e única. Depois, afirma-se a positividade da infância como experiência única de entrada na linguagem e de constituir história e como pensamento crítico, tomando Giorgio Agamben e René Schérer como interlocutores. Ao final, indicam-se três obstáculos para a realização de pesquisas descolonizadas com crianças e os temas que necessariamente fazem parte da temática pós-colonial como raça, gênero, etnia, Estado-nação e diáspora, a partir das autoras Judith Butler, Gayatri Spivak e Avtar Brah.
\end{abstract}

Palavras-chave: Infância, Pesquisa com crianças, Pensamento Crítico, Estudos Pós-Coloniais.

\section{DECOLONIZING RESEARCH WITH CHILDREN AND THREE OBSTACLES}

ABSTRACT: This article discusses the possibilities for decolonizing research with children through an understanding of childhood conceived as a unique social and individual experience that decentralizes or avoids hegemonic places and models that centralize dominant senses, norms, aesthetics and health and that is constituted beyond the logic of capital. It starts the debate focusing on childhood as a power device that is imposed upon each child in a single and universal manner, and then it claims the positivity of childhood as a unique experience of entering language and constituting history and as critical thinking, taking Giorgio Agamben and Rene Scherer as interlocutors.

\footnotetext{
* Departamento de Teorias e Práticas Pedagógicas da Universidade Federal de São Carlos (Ufscar). São Carlos (SP) - Brasil. Bolsista Produtividade 1C do CNPq.

* Departamento de Teorias e Práticas Pedagógicas da Universidade Federal de São Carlos (Ufscar). São Carlos (SP) - Brasil.

Contato com as autoras: <aneteabramo@gmail.com>
} 
At the end we indicate three obstacles to conducting decolonized research with children and the topics that necessarily form part of the post-colonial set of themes such as race, gender, ethnicity, nation-state and Diaspora, based on the work of Judith Butler, Gayatri Spivak and Avtar Brah.

Key words: Childhood. Research with children. Critical thinking. Post-colonial studies.

\section{DeColonisant LES RECHERCHES AVEC DES ENFANTS ET TROIS OBSTACLES}

RÉSUMÉ: Cet article aborde les possibilités de décolonisation des recherches avec des enfants, grâce à la compréhension de l'enfance comme une expérience sociale unique et individuelle qui décentralise ou fait fuir des modèles hégémoniques qui centralisent les sens, les règles, l'esthétique et la santé et qui devient dominant au-delà de la logique du capital. On commence le débat sur l'enfance en tant que dispositif de pouvoir qui s'impose à chaque enfant de manière universelle et unique, ensuite il constate l'expérience positive de l'enfance comme la seule possibilité d'entrée dans le langage et de constituer histoire et comme une pensée critique selon Giorgio Agamben et René Scherer. A la fin on indique trois obstacles à la recherche décolonisées auprès des enfants et les thèmes qui font forcément partie des thèmes post-coloniaux tels que la race, le sexe, l'origine ethnique, l'État-nation et de la diaspora selon les auteurs Judith Butler, Gayatri Spivak et Avtar Brah.

Mots-clés: Enfance. Recherche avec des enfants. Pensée critique. Études postcoloniales.

$\mathrm{E}$ ste artigo, preparado para o I Seminário Internacional sobre Infâncias e Pós-Colonialismo: pesquisas em busca de pedagogias descolonizadoras, tem como foco de discussão o debate sobre os conceitos de infância, de criança e das pedagogias descolonizadoras.

Para introduzir a temática em relação a como descolonizar as pesquisas com crianças é preciso indicar que estamos entendendo o processo de descolonização no interior de uma das possibilidades de constituir-se de maneira singular, produzindo e criando novas/outras possibilidades de vida, de criança(s), de infância(s) e de pesquisa(s). Isso implica a necessidade de criar instrumentos, ferramentas teóricas, conceitos, afectos e perceptos que possibilitem a constituição social/individual de formas singulares de existências, coletivas ou não. Descolonizar é produzir uma processualidade na qual é possível constituir experiências sociais e individuais singulares, que descentralizem, ou façam fugir os modelos e lugares hegemônicos que centralizam sentidos, norma, estética, saúde, entre outros, dominantes e que se constituam para além da lógica do capital.

Para iniciar o debate gostaríamos de retomar o próprio conceito de infância. Na historia da filosofia a criança foi durante muito tempo entendida como negatividade. 
Se tomarmos a pedagogia tradicional, por exemplo, a infância é, então, interpretada com referência a tudo que se passa como antítese da humanidade verdadeira: a animalidade, a selvageria, a morte (preferível à infância, segundo Santo Agostinho ${ }^{1}$ ), a doença (Aristóteles), a loucura (Platão). Se a infância é assim rebaixada, é porque a humanidade é idealizada: a infância é definida por oposição à sabedoria e à santidade. Comparada com esses estados, ela é um quase nada, é uma pura insuficiência. A insuficiência, a negatividade, a corrupção da criança fundam, na pedagogia tradicional, o direito do adulto à intervenção. A criança deve ser submetida a uma vigilância constante, não deve fazer nada por si mesma, o adulto deve mostrar-lhe tudo. É em Nietzsche (1997), no livro Assim falava Zaratrusta, que as crianças serão consideradas em sua positividade, na medida em que ele considerou a criança, na descrição das três metamorfoses do espírito, como sendo o último estágio do espírito humano. Quando o homem chega à criança, é um novo recomeço, não mais o camelo que carrega o fardo da história e dos valores, nem mesmo o leão que diz não aos valores, mas a criança que inaugura o novo. Uma positividade se instaura na filosofia ao olhar a criança.

Nesta vertente, que poderíamos dizer positiva em relação à criança que temos trabalhado, a infância é primeira e condição de linguagem, ao contrário de seu termo etimológico: "sem fala". A partir de Nietsche, mais especificamente em Agamben (2005), encontramos a ideia de que a única possibilidade de fala que se tem é quando se é infante. Ou seja, a ideia de que se não entramos na linguagem na infância, não entramos mais. A infância é aquela que realiza a experiência do acesso à linguagem, pois a linguagem não está dada, já que não é nem o olfato e nem paladar, é uma experiência que deve ser feita necessariamente na infância.

Giorgio Agamben, particularmente na obra Infância e história, mostra-nos muito sugestivamente que, se bem é verdade que a infância é a ausência de linguagem, não é menos verdade que a adultícia é a ausência da possibilidade de se inscrever na linguagem, porque já se está dentro dela, ou porque se impossibilitou de entrar durante a infância. Em outras palavras, se tirarmos os casos excepcionais, são sempre as crianças e não os adultos que aprendem a falar. Quem entra na linguagem pela primeira vez é a infância, a aprendizagem da linguagem está ligada à disposição infantil; ao abandonarmos a infância, deixamos a possibilidade de entrar na linguagem. (KOHAN, 2007, p. 122)

Contudo, antes da infância se tornar esta positividade, ou em concorrência a esta visão, na qual Nietzsche colocou a criança em um estágio superior do desenvolvimento do espírito humano, ela tem atuado como um dispositivo de poder, que universaliza uma ideia de infância, única e generalista e consagra a todas as crianças, independente de qualquer singularidade, a mesma infância. As pedagogias trabalham na direção desta infância, única.

Nesse sentido, temos compreendido a infância como um forte dispositivo que atua capilarmente sobre as crianças, produzindo-as e definindo uma mesma infância, 
sem que a própria criança tenha condições de se interrogar sobre ela. É nesta direção que os antropólogos da infância têm indicado a impossibilidade de pensar uma infância indígena longe do trabalho, ou mesmo se perguntado se infância é um conceito que faria sentido na criança indígena, já que ela se torna indígena de determinada aldeia pela via do trabalho, e a infância é consagrada pela ausência de trabalho.

Há um preceito hegemônico que fala de infância e da potência da criança sob os auspícios da economia, como investimento social e capital do futuro, e sobre esta perspectiva é que muitas das pesquisas têm sido elaboradas e financiadas.

\title{
Infância e pensamento crítico
}

Paolo Virno (2012, p. 34), filósofo italiano e semiólogo, afirma: “Não é concebível um pensamento crítico que não seja também, em quaisquer de suas facetas, uma meditação sobre a infância". Ele ainda nos coloca:

\begin{abstract}
De Rousseau às comunas antiautoritárias de 1968, a atenção dos reformadores e revolucionários para com o ser humano principiante resultou em pedagogia. Isto é, na tentativa de colocar a formação da criança de acordo com o ideal de uma sociedade mais justa. Deste modo, menosprezou-se a autêntica questão: extrair da própria experiência infantil critérios e conceitos capazes de iluminar ulteriormente as relações sociais e de produção, mas também esboçar a crítica. Invertendo a perspectiva pedagógica, é da infância que é necessário esperar instruções. (Idem, ibid.)
\end{abstract}

É a infância que deveria iluminar todas as pesquisas sobre crianças, o trabalho na educação infantil, as perspectivas singulares de se constituir experiências sociais, pois é ela quem carrega a possibilidade de mudança. O que significa dizer que existe uma infância? Ao dizermos isto estamos dizendo muitas coisas, e coisas díspares. Por um lado, a infância é uma construção social, produzida e engendrada no interior de uma série de normas, de leis, de medidas, de pressupostos, que vão dos filosóficos aos teológicos, dos jurídicos aos pedagógicos e psicológicos. Estamos também, sobretudo, convergindo com as discussões que problematizam certa naturalização da infância, compreendida como fase de desenvolvimento da criança, ou como uma fase biológica do desenvolvimento humano, igualmente sobreposta a todas as crianças.

Ao contrário, nossa perspectiva é pensar de que maneira a criança pode ela própria interrogar sua infância, de que maneira a criança pode infletir, interrogar, subtrair e resistir à ideia de infância, quando ela se apresenta como um dispositivo fabricado e, de certa maneira, garantidor de um funcionamento da sociedade. $\mathrm{O}$ nosso desafio é empreender um esforço posto por Deleuze e Guattari, que concebem "a ideia de um adulto modulado pela criança, a ideia de que o homem precisa 
do devir criança para conseguir desfazer os modelos consensuais anteriores ao seu próprio pensamento (SCHÉRER, 2009, p. 66). Esta ideia é fabulosa, pois é a criança interrogando sua infância como uma possibilidade de resistir, como um poder da vida se opondo ao poder sobre a vida; a própria ideia de infância como aquela capaz de descolonizar a pesquisa com crianças.

René Schérer concebia também uma anterioridade do adulto sobre a criança, que é modelada à sua imagem. Uma das ideias centrais em que ele insiste é a de que existe uma anterioridade do adulto sobre a criança, que é ficcionada e modelada à sua imagem. O que faz com que a criança não seja mais do que uma potência, um potencial que a sociedade protege e põe de parte, como que em reserva, prometendo-lhe um futuro que, por vezes, a deixa desprovida de presente (idem, ibid.). A questão é que há uma infância que modela a criança. Quem concebe a infância é o adulto, que a pensa de maneira pregressa e assim retira a potência e a possibilidade de transformação que há na própria infância. A criança está empobrecida no aluno, no pequeno consumidor, empobrecida em ideias pré-concebidas de infância.

Sabemos já, infinitamente, que a infância é uma construção social, uma invenção territorializada na Modernidade, com funções estratégicas muito específicas e oportunas. Essa noção, contudo, não é nova. Em 1960, em seu livro que se consagrou como um marco nos estudos da infância, Ariès reúne com certo fôlego, apesar das inúmeras críticas, a ideia de que a infância é uma construção social da Modernidade, consolidada principalmente no século XVIII. Encontraremos esta ideia também escrita anteriormente, em 1940, quando Florestan Fernandes, ao pesquisar os processos de socialização das crianças do Bom Retiro, elucida as bases sociais para a construção do que ele chamará de cultura infantil, no interior da ideia de infância. Em 1937, Marcel Mauss também evidencia uma noção convergente a esta, no texto Três observações sobre a sociologia da infância, apresentação que faria no Congresso de Sociologia da Infância.

O que pretendemos indicar é que, se a infância é uma construção social, uma invenção, produzida de muitas maneiras, especialmente pelas normatizações jurídicas, torna-se um poderoso dispositivo do poder. Ou seja, a infância tem pensado e configurado a criança como um determinado aluno, determinada forma, estética, raça etc., e infância e criança única. É nesta direção que iremos destacar que a infância é, na verdade, e, nesse sentido, um dispositivo do poder. E, ao mesmo tempo, é a própria criança que, em seu devir, resiste e interroga a infância.

\section{A infância como um dispositivo do poder: algumas explanações}

Foucault (1977) trabalha longamente com a noção de dispositivo, especialmente no esforço teórico em mostrar que a sexualidade é um dispositivo histórico 
do poder. ${ }^{2}$ Mas não há nenhum texto de Foucault no qual ele se detém para elucidar ou construir o conceito. Encontraremos um pouco deste esforço de formulação conceitual de dispositivo em Agamben (2007)³ e em Deleuze (1999).

Para nós, o conceito de dispositivo é profícuo, no sentido de convergir com a noção de que as crianças são produzidas no interior de um conjunto heterogêneo de práticas, discursivas e não discursivas, e pelo fato de que a noção de dispositivo e de infância carrega uma formulação "positiva" do poder, tal como formulada por Foucault.

A ideia de Foucault tão largamente debatida é a de que o poder é positivo, ou seja, que ele produz corpos, desejos etc. Em poucas palavras: o poder não diz só não, ele diz sim, ele é construtivo. Nesse sentido é que afirmamos que a infância é um dos dispositivos que se inscreve sobre a criança. Esta produção é dada de tal maneira que já não conseguimos mais separar a criança da infância, ou seja, não há nenhum momento na sociedade ocidental onde a criança esteja separada da infância, pois o dispositivo da infância atua de maneira capilar sobre a criança, produzindo-a.

Sabemos dos debates ocorridos, especialmente na década de 1970, sobre a ideia de que as crianças pobres não tinham infância, já que a desigualdade social as impediria de fazer usufruto desta espécie de "bolsão" protetor da criança que seria a infância. Mas já nesta visão da criança sem infância, o dispositivo atua, mesmo que como falta, ou seja, a criança pobre é vista como faltante no interior disso que é a infância. Esta ideia das crianças pobres sem infância foi sendo substituída pela noção de que a infância era e é uma condição da criança; nesta visão é inseparável ser criança e usufruir de uma infância.

\section{A emergência da infância}

O que é a infância? Foucault (1977) se pergunta se infância não constituiria justamente a liberdade de não ser adulto, de não depender da lei e de poder estabelecer relações polimorfas com as coisas, com as pessoas e com os corpos? É isto que a infância não pode mais: produzir o adulto e não ser produzido por ele.

Ao investigarmos os processos que produziram a ideia de infância, tal como conhecemos hoje, observamos que sua construção se dá no interior de uma "vontade de verdade" sobre as crianças, na qual diferentes discursos são proferidos, a fim de gerir o que se fala sobre, para quem se fala e por que se fala sobre a criança. Nesta direção, longe de ser uma relação polimorfa e também longe de ser a "realidade subterrânea" da vida e da existência da criança, a infância é, sobretudo, uma invenção produzida e elaborada nas relações que se efetivam em uma "vontade de saber" sobre a criança (FOUCAULT, 1977). 
A investigação sobre o processo de construção e produção da infância nos leva aos estudos desenvolvidos pelo historiador francês Philippe Ariès (1960), para quem a infância pode ser compreendida como uma singularidade que se expressa em um sentimento, o qual ele chamou de "sentimento de infância". O que nos interessa neste estudo é que este sentimento de infância demarca uma especificidade para a criança, por meio da qual se produzirá a infância. Ou seja, o sentimento de que a criança era inocente e precisava ser protegida faz com que se produza todo um ordenamento novo de educação e governamento das crianças, colocando sobre elas imperativos, ou dispositivos, entre eles o higiênico-pedagógico, o jurídico, o médico, e que se juntarão aos dispositivos literários, do brinquedo e de tantos outros que buscam normatizar, normalizar e moralizar a criança (ABRAMOWICZ; RODRIGUES; MORUZZI, 2012).

Segundo o autor, o que está em jogo neste momento é, na verdade, a gerência da população. As crianças emergem socialmente porque são a representação do corpo fraco, indócil e débil, fase inferior do desenvolvimento humano e, por isso mesmo, representam maior possibilidade de intervenção, de gerência e de educação. Em todas as instâncias do saber, seja da medicina, da psiquiatria ou da psicologia, a criança emerge como indivíduo perigoso e em perigo, fraco emocionalmente e fisicamente e, ao mesmo tempo, forte, dotado de uma imensa capacidade plástica para aprender e adquirir novos hábitos. São imagens que variam entre a criança pobre e carente (o lugar da falta), ou a infância em perigo, e os pequenos marginais (o lugar do excesso), ou a infância perigosa. De "bons e pobres selvagens" a "maus e selvagens". A infância em perigo precisaria de cuidado e proteção e a infância perigosa, de limite e contenção. São imagens que elucidam o modo como, no imaginário social, a ideia de infância, associada aos sentimentos de ingenuidade, inocência, impertinência, foi sendo capilarmente construída na sociedade ocidental.

\section{Palavras finais}

Há que se restabelecer as distribuições de posição, de lugar e de poder entre adultos e crianças, de maneira a emancipar e dar autonomia às crianças, segundo Schérer (2009, p.65): "pensar uma infância maior, emancipada, infantil, mas não infantilizada". Na trilha deste pensamento, o que temos que nos esforçar em fazer é subtrair o consenso maioritário, que seria o devir em Deleuze e Guattari, ou a "história a contrapelo" em Walter Benjamin. É pensar as políticas para a criança a partir do conceito positivo de infãncia.

Descreveremos a seguir três obstáculos para a realização de pesquisas descolonizadas com crianças que gostaríamos de indicar. 


\section{Obstáculo 1}

O primeiro obstáculo é que a universidade brasileira está cada vez mais longe de uma possibilidade de produzir pesquisas descolonizadas. Nunca estivemos tão dentro de uma lógica neoliberal que introduziu a todos na perspectiva produtivista, à qual temos tido muitas dificuldades em resistir. $\mathrm{O}$ curioso é que a lógica neoliberal a que as universidades aderiram, cujos efeitos são a competição, o ranqueamento e o produtivismo, nos tirou essencialmente algo que é central no entendimento da infância: o tempo. Não há mais o tempo como o concebemos em sua textura, em sua largueza... lassidão... Vivemos neste momento uma subtração do tempo. No neoliberalismo, ao contrário daqueles que o compreendem como ausência ou o mínimo de Estado associado a uma regulação social realizada pelo mercado, na realidade não há ausência de Estado, mas sim a interferência deste na produção da lógica concorrencial entre os pares (cf. LAZZARATO, 2011). O Estado tem por função produzir a concorrência, por isso a avaliação tem sido central nas políticas públicas e aos poucos chegará na educação infantil, como sabemos. Concorremos entre nós, para assegurar os parcos recursos financeiros destinados pelas agências de fomento de pesquisa para a educação e para as ciências humanas, seja em bolsas ou em financiamento de pesquisa. Somos incitados, como bem disse Foucault, a produzir; o poder é produtivo, ele não repreende e nem reprime, ele não diz não e não é ideológico, ele é produtivo, nos produz e nós somos partícipes ativos desta lógica - "o que temos feito de nós mesmos, perguntava Foucault" -, sem que ninguém nos obrigue, trabalhamos e produzimos incessantemente, e nosso tempo - o tempo de infância no qual a criação acontece, pois ninguém cria sem um tempo largo e generoso - nos foi tomado, abrimos mão do tempo, da infância, e nos deixamos colonizar pelo capital, pelo poder, e vivemos sem o tempo para a criação. Os processos criativos são imprescindíveis para que a pesquisa aconteça, porque, ao pesquisar, investigamos numa linha extremamente tênue daquilo que não sabemos, pois se pesquisar é achar o que já vimos, isto nada tem a ver com pesquisa; e se pesquisamos o desconhecido, é preciso experimentar estas forças, as forças do caos, da incompletude, da indeterminação... Enfim, precisamos da criação e da arte - que são totalmente afins com o caos e com o pensamento - para que possamos daí extrair uma nova/outra possibilidade de vida.

Não se faz pesquisa sem o tempo. Ou seja, o primeiro obstáculo que se coloca é: Como a universidade se constitui para além da lógica do poder/saber e do capital?

\section{Obstáculo 2}

O segundo obstáculo a ultrapassar e que temos escutado não sem preocupação e com muitas dificuldades de enfrentamento, já que é estrutural na pedagogia, é o desejo de prescrição. Os alunos de pedagogia e os professores em sua prática 
educativa querem a prescrição, o como, como se faz; é a pergunta primeira e imediata. Pergunta-se a outro: "como eu devo fazer"? Pesquisadores têm abandonado a discussão sobre o desejo de prescrição e aberto mão de uma construção analítica que é também prática, na tentativa de responder o "como", como se fosse possível que este fosse uma prescrição elaborada por professores fora do campo onde a prática se dá, e em condições muito distintas dos modos de produzir o seu fazer. Dizer ao outro como fazer é uma indignidade de dizer pelo outro. Os professores e muitos alunos abandonaram o campo de batalha e querem o como. Deleuze se pergunta: "o que pode o pensamento quando todas as forças que nos atravessam nos querem fracos, servos e tolos"? As forças que nos atravessam nos fragilizam, nos impõe uma servidão voluntária. Deleuze não deixou sem resposta a sua própria pergunta inquietante. Criar. Há que se opor à prescrição. Mas não tem sido fácil, pois há aqueles que se arrogam capazes de responder e inundam o campo teórico e prático de manuais: ensino de ciências, matemática, português, inglês, judô na educação infantil, o que ensinar aos bebês, quem tem medo de ensinar, como ensinar, em que momento etc. Precisamos nos opor às pedagogias suplicantes e prescritivas. Não há descolonização que possa ser feita sob o desejo voluntário de servidão (LA BOÉTIE, 1982). Não é fácil escapar, pois em nome da escola colonizou-se a pré-escola e as creches. Por isso, a questão de um pesquisador não é apresentar opiniões - para serem debatidas -, mas constituir problemas - para serem pensados -, o que não é fácil.

\section{Obstáculo 3}

O terceiro obstáculo diz respeito ao processo de descolonização. Sabemos que os temas centrais colocados no campo pós-colonial e pós-estrutural são aqueles relativos às diferenças, a diversidade, a hibridação etc. Estes temas trazem em seu rastro a questão do antirracismo, do multiculturalismo, o feminismo, entre outros. Ou seja, são temas que tomam a questão da nacionalidade, do território, coloca em questão o que é o Estado-nação, a questão da língua. Judith Butler, em conversa com Gayatri Spivak (2009), se pergunta por que não podemos cantar os hinos nacionais em várias línguas, referindo-se à reivindicação em se cantar o hino dos Estados Unidos em espanhol. Muitos vieram tardiamente discutir diferenças, pois achavam que, de alguma forma, o problema de raça, gênero, sexualidade e etnia era ideológico, simbólico e que fazia parte de uma superestrutura como uma espécie de poeira que se desprega da base material. A materialidade das diferenças, das relações étnicoraciais, sexuais, entre outras, e as dificuldades de enfrentá-las tornaram-se temas centrais para as políticas públicas.

O que são diferenças? Como lidar com elas? A questão é que fomos assujeitados e nos constituímos como sujeitos neste processo e, deste modo, "equipados" para lidar com as coisas e com o mundo, com uma determinada percepção e consciência, 
por exemplo, que são completamente insuficientes para enfrentar a diferença, o preconceito e o racismo. Desse modo, propostas como tolerância, paciência e consciência são absolutamente ineficazes, pois ninguém, pelo menos no campo da educação, nenhum professor quer ser racista e homofóbico, por exemplo, mas o é, efetivamente, apesar de toda a consciência que possui. Sob o manto da diversidade, o reconhecimento das várias identidades e/ou culturas vem sob a égide da tolerância, tão em voga, já que pedir tolerância ainda significa manter intactas as hierarquias do que é considerado hegemônico. Além disso, a diversidade é a palavra-chave da possibilidade de ampliar o campo do capital, que penetra cada vez mais em subjetividades antes intactas.

Vendem-se produtos para as diferenças, e nesse sentido é preciso incentiválas. Ou seja, a diversidade foi entendida como uma forma de governamento exercido pela política pública no campo da cultura, como uma estratégia de apaziguamento das desigualdades e de esvaziamento do campo da diferença, que tem como função borrar as identidades e quebrar as hegemonias.

Algumas palavras sobre os temas centrais para aqueles que pretendem realizar pesquisas no rastro da descolonização. O primeiro entrave epistemológico é a própria linguagem e a própria gramática. Somos totalmente prisioneiros de uma linguagem que se constitui como hegemônica e de sua gramaticalidade. Nesta linguagem não se pode gaguejar, não se pode ter lapsos, esquecimentos e nem mesmo hesitação. A centralidade desta linguagem é a escrita, a oralidade é subalternizada. Neste jeito hegemônico de falar e de constituir o real, já que na verdade a linguagem cria o real e as verdades, estão excluídos aqueles que não se expressam deste modo como as crianças, por exemplo. As crianças não escrevem. E há sociedades com uma forte ênfase oral. A história oral é um instrumento que preserva o entrelaçamento entre história e subjetividade. Para isso, é preciso levar-se em conta os gestos, o timbre e o tom da voz, a política do rosto, a expressividade do olhar etc., e pouco entendemos sobre isso.

O pesquisador americano William Corsaro, sociólogo da infância, na sociologia americana compreendeu que, para escapar da hierárquica relação adulto-criança, precisava tirar de si algo fundamental: a língua. Assim, foi fazer sociologia da infância na Itália sem saber falar italiano. É exatamente isso que precisamos para entender a criança: é falar em outra língua, para poder responder à questão central posta pela sociologia da infância: "qual é a perspectiva que temos que adotar para entender a perspectiva das crianças?".

Segundo um escritor, sociólogo, crítico literário, semiólogo e filósofo francês denominado Roland Barthes, a linguagem não é nem progressista, nem reacionária, ela é simplesmente fascista; ela nos obriga a dizer certas coisas, a ocupar certos lugares, posições homem-mulher, mestre-aluno, branco-negro, direita-esquerda. A primeira pergunta que se impõe é: "como driblar os sentidos impostos, os lugares prévios? 
Como introduzir a hesitação, a indecisão, os estados de suspensão? Como sustentar um discurso sem impô-lo? Como fazer do próprio ensino um exercício de deriva e de desaprendizagem?" (PELBART, 2005, p. 11).

\section{Raça/gênero/sexualidade}

O tema da raça é central, e é importante ter claro que não há política educacional que não traga em si uma concepção de raça e de sexo. Estes debates estão na pauta do Estado e dos movimentos sociais. Não há nenhuma possibilidade de se fazer pesquisa hoje sem que a linha raça seja percorrida. No Brasil, o debate nacional em educação sobre raça foi colocado e circunscrito no âmbito do currículo e da cultura. Este é um longo debate que não faremos aqui. A opção culturalista no Brasil velou o referencial racialista, impresso principalmente nas políticas educacionais. ${ }^{4}$

De toda maneira, queremos dizer que a ideia de cultura tem servido como tropo de raça, como diversidade, como diferença, como resposta curricular dada pelas políticas públicas aos movimentos sociais que reivindicam reparação e/ou representação cultural (dos sentidos singulares que atribuem às coisas e ao mundo), como clave genérica que se atribui às "coisas" (as múltiplas possibilidades de sentido dadas por grupos sociais) que não se conhece exatamente, como capaz de, por esta via, equalizar os problemas das desigualdades/diferenças presentes na escola. Temos usado indiferentemente diversidade e diferença, e a função desta indiferenciação é uma armadilha conceitual, pois utilizamos a diversidade sem desigualdade e utilizamos o conceito de diversidade de maneira a esvaziar a diferença; ao fazermos isso, é uma estratégia que a diferença não faça diferença nenhuma. E é nesse sentido que o que se tem feito é uma espécie de "justiça cultural" no lugar, ou como substituição de uma justiça social.

\section{Por fim}

Precisamos de uma educação não fascista que é aquela que concebe a infância como experiência, aceita um currículo pautado no pensamento nômade e vê no espaço-tempo da aula a possibilidade do ato de criação.

O que temos nas várias abordagens pedagógicas e nas ações que lhes servem de corolário é uma subalternização de relações em nome de um contrato social em que o indivíduo é educado para um lugar definido na sociedade, seja o de opressor, seja o de oprimido, reacionário ou revolucionário, alienado ou socialmente consciente, etc. Ser diferente, nessa perspectiva, dá ao indivíduo uma nuance patológica.

Como criar e produzir um espaço fora das amarras de sentido, da ideia de infância/ povo, uma espécie de espaço fora-da-infância, uma banda larga, uma margem maior, 
que nunca se sabe exatamente aonde se vai chegar, em que as crianças possam ficar sós, pensar, grunhir, falar, etc.?

Se se quer produzir diferença é porque ela está ali e precisa fazer valer sua potência política, precisa ser tirada do lugar do estranho, do horrível e da aberração. Mas isso num movimento não de conversão em lucro para o capital, que tem sido hábil em lhes retirar o que têm de único e talvez último, que são sua potência e sua vida. A diferença precisa ser retirada da cena onde foi satanizada para ser recolocada na multidão, onde a paisagem é indefinida, onde não se sabe exatamente quem é quem e o que é o que, mesmo porque ela é nômade: quem estava ali não está mais, quem chegou já saiu.

A educação de crianças pequenas coloca-as no espaço público, que deveria ser um espaço não fraternal, não doméstico e nem familiar. Queremos dizer com isso que o espaço público é aquele que permite múltiplas experimentações. É o espaço, por excelência, da criação, em que se exercitam formas diferentes de sociabilidade, subjetividade e ação, o que não é possível em espaços familiares, que priorizam a segurança material e imaterial. O espaço público expõe e possibilita à criança outros agenciamentos, afetos e amizades. É preciso saber aproveitar as possibilidades de acontecimentos que se inauguram na cena pública e escolar. A professora não é a mãe, nem a tia; a colega não é a irmã; e brincar de casinha não é imitar papai-e-mamãe, bem como as histórias infantis não precisam remeter a um final feliz e nem à ideia de mulher, de casal e de povo. Nessa educação, a professora está fortemente empenhada em entender o que as crianças falam, o que querem conhecer, o que há de interessante a fazer e a deixar de fazer, a estudar, deixar para lá; pensar o que há de interessante para visitar, que novas formas de brincar podem ser brincadas, que músicas e que danças podem ser inventadas. Talvez valha a pena aproveitar a ideia das cem linguagens preconizada pela escola italiana no interior de uma educação com a criança, no espaço público, em que as afectibilidades criem novas redes de solidariedade e pensamento para que se possibilite um devir-criança. (ABRAMOWICZ; LEVCOVITZ; RODRIGUES, 2009)

Para pensarmos uma educação e pesquisa descolonizada precisamos adotar uma perspectiva também descolonizada. Para tanto, utilizamos um conceito da pós-colonialista Avtar Brah, o de diáspora, e achamos que a educação infantil deveria se constituir como um espaço de diáspora. Um espaço assim não é a pátria idealizada e homogênea. É uma inflexão territorial e temporal (em uma concepção de tempo que junta a historia dos que vieram com aqueles que já estão e os que virão) operada pelos coletivos sociais a partir da racialização, do gênero, da sexualidade e da etnia; pois cultura tem significado pluralidade do mesmo, pois usamos cultura para não dizer raça, etnia e/ou diferenças radicais. $\mathrm{O}$ conceito cultura passou a ser utilizado quase como o conceito de biológico, um conceito universal que perdeu aquilo que se pretendia evidenciar: singularidades. $\mathrm{O}$ fato dos brancos não se verem de maneira racializada deriva da noção de que o branco é um significante de dominação, assim como o heterossexual. Portanto, o espaço de diáspora são espaços locais que atravessam todos os lugares de maneira imanente, de forma que os grupos sociais - não só os migrantes, mas os que são excluídos - infletem os espaços/territórios tornando-os "o seu lugar". O lugar então, sem origem fixa, congrega só diferenças.

Enfim, não se pode saturar a vida com tanta identidade! 


\section{Notas}

1. “Durante longos séculos, a teologia cristã, na pessoa de Santo Agostinho, elaborou uma imagem dramática da infância. Logo que nasce, a criança é símbolo do mal, um ser imperfeito esmagado pelo peso do pecado original. Em A cidade de Deus, Santo Agostinho explicita longamente o que entende por 'pecado de infância'. Descreve o filho do homem, ignorante, apaixonado e caprichoso: 'Se o deixássemos fazer o que lhe agrada, não há crime que não se precipitaria'”' (BADINTER, 1980, p. 55).

2. Para este debate, há uma tese de Moruzzi (2012), que realizou esta discussão em profundidade.

3. Para este debate, ver Moruzzi (op. cit.).

4. Este debate está aprofundado na tese de Rodrigues (2011).

\section{Referências}

ABRAMOWICZ, A.; LEVCOVITZ, D.; RODRIGUES, T.C. Infâncias em educação infantil. Pro-Posições, Campinas, v. 20, n. 3, p. 179-197, set./dez. 2009.

ABRAMOWICZ, A.; RODRIGUES, T.C.; MORUZZI, A.B. O Plano Nacional de Educação e a normatização da infância, educação infantil e PNE. Campinas: Autores Associados, 2012. p. 83-102.

AGAMBEN, G. Infância e história. Belo Horizonte: UFMG, 2005.

AGAMBEN, G. Qu'est-ce qu'um dispositif? Paris: Payot, 2007.

ARIÈS, P. L'enfant et la vie familiale sous l'ancien Régime. Paris: Seuil, (1960) 1973.

BADINTER, E. Um amor conquistado: o mito do amor materno. Trad. de Waltensir Dutra. Rio de Janeiro: Nova Fronteira, 1980.

BRAH, A. Cartografías de la Diáspora: identidades en cuestión. Madrid: Traficantes de Sueños, 2011.

BUTLER, J.; SPIVAK, G.C. Quién le canta al Estado-nación?: lenguaje, política, pertenencia. Buenos Aires: Paidós, 2009.

CORSARO, W.A. Sociologia da infância. Trad. de Lia Gabriele Regius Reis. Porto Alegre: Artmed, 2011.

DELEUZE, G. Que és un dispotivo? In: BALIBAR, E. et al. Michel Foucault, filósofo. Barcelona: Gedisa, 1999. p. 155-163

FERNANDES, F. Folclore e mudança social na cidade de São Paulo. Petrópolis: Vozes, 1979.

FOUCAULT, M. História da Sexualidade I: a vontade de saber. 3. ed. Rio de Janeiro: Graal, 1977. 
KOHAN, W. Infância, estrangeiridade e ignorância: ensaios de filosofia e educação. Belo Horizonte: Autêntica, 2007.

LA BOÉTIE, E. Comentários de Claude Lefort, Pierre Clastres e Marilena Chauí: discurso da servidão voluntária. São Paulo: Brasiliense, 1982.

LAZZARATO, M. O governo das desigualdades: crítica da insegurança neoliberal. Trad. de Renato Abramowicz Santos. São Carlos: Ufscar, 2011.

MAUSS, M. Três observações sobre a sociologia da infância. Pro-Posições, Campinas, v. 21, n. 3, p. 237-244, dez. 2010.

MORUZZI, A.B. A pedagogização do sexo da criança: do corpo ao dispositivo da infância. 2012. Tese (Doutorado em Educação) - Universidade Federal de São Carlos, São Carlos.

NIETZCHE, F. Assim falava Zaratustra. [s.1.]: Ediclube, 1997.

PELBART, P.P. Deleuze e a educação. In: ABRAMOWICZ, A.; SILVÈRIO, V. (Org.). Afirmando diferenças: montando o quebra-cabeça da diversidade na escola. Campinas: Papirus, 2005. p. 9-13.

RODRIGUES, T.C. A ascenção da diversidade nas politicas educacionais contemporâneas. 2011. Tese (Doutorado em Educação) - Universidade Federal de São Carlos, São Carlos.

SCHÉRER, R. Infantis, Charles Fourier e a infância para além das crianças. Belo Horizonte: Autêntica, 2009.

VIRNO, P. Infância e pensamento crítico. Imprópria: política e pensamento crítico, Lisboa, n. 2, 2012.

Recebido em 3 de maio de 2013.

Aprovado em 30 de outubro de 2013. 